\title{
UNIKÁTNY NÁLEZ PLUTVOVITÉHO NÁKONČIA POŠVY Z IVANOVÍC NA HANÉ, OKR. VYŠKOV, V KONTEXTE VÝVOJA DOBY POPOLNICOVÝCH POLÍ NA MORAVE ${ }^{1}$
}

\author{
David Parma - Susanne Stegmann-Rajtár
}

\author{
DOI: https://doi.org/10.31577/szausav.2019.suppl.1.22
}

Keywords: Moravia, Late to Upper Bronze Age, fin-shaped chape, regional and supraregional contacts, settlement structure

\begin{abstract}
A unique find of a fin-shaped chape from Ivanovice na Hané, Vyškov district, in the context of development of the Urnfield culture in Moravia

Important finds discovered during extensive rescue researches along the D1 motorway between Brno and Kroměřǐz include a find of a fin-shaped chape. It comes from the site of Ivanovice na Hané, site 7 Spravedlnost, Vyškov district. It is a unique find without a more specific find context. It was discovered with a metal detector during prospecting. This unique type of chape, which was probably an import, points to contacts with regions of the North Black Sea coast and North Caucasus, where it is classified as a so-called Cimmerian bronze. Its closest parallel comes from Moravia, cremation burial 169 at the burial ground in Brno-Obřany, which - on the basis of relative chronology - belongs to the Late or Upper Bronze Age. It is the third exemplar of a fin-shaped chape (probably of a dagger or a sword) in Central Europe.
\end{abstract}

\section{ÚVOD}

V posledných dvoch desatročiach sa $\mathrm{v}$ priestore Vyškovskej brány podarilo získat početné informácie a nové dáta $\mathrm{k}$ riešeniu problematiky osídlenia tohto regiónu $\mathrm{v}$ praveku a včasnej doby historickej. Výrazne $\mathrm{k}$ tomu prispela realizácia vel'koplošných záchranných výskumov, kde sa objavili aj doteraz neznáme archeologické náleziská. Výskum na trase dialnice v polohe Ivanovice na Hané $7 \mathrm{v}$ rokoch 2002 a 2003 priniesol doklady intenzívneho osídlenia predovšetkým zo staršej a mladšej doby bronzovej (BD a HA2), d’alej menej výrazné aktivity z neolitu a strednej doby bronzovej, ako aj ojedinelé hroby zo záveru eneolitu a počiatku doby bronzovej. Plošná geomagnetická prospekcia v roku 2014 upresnila rozsah zistených sídliskových komponentov a identifikovala juhozápadne od trasy dial’nice d’alšie komponenty s pravouhlými zahĺbenými objektami, najpravdepodobnejšie išlo o sídliskové areály doby laténskej alebo doby rímskej. Na základe nálezového materiálu ide o kontaktný priestor dvoch vel'kých kultúrnych okruhov - kultúry stredodunajských popolnicových polí a lužickej kultúry (Parma 2015; Parma/Šmíd 2013; Parma/Holubová 2015; Parma/Holubová/Rybářová 2016, 23, obr. 1; Podborský a kol. 1993, 309, mapa 24).

\section{K OSÍDLENIU VYŠKOVSKEJ BRÁNY V DOBE BRONZOVEJ A HALŠTATSKEJ}

Osídlenie Vyškovskej brány v dobe bronzovej a halštatskej bolo aktuálne vymapované na základe reprezentatívneho súboru dát; jedným zo záverov vyplývajúcich z historických štúdií osídlenia je výrazná diskontinuita sídliskovej siete od počiatku neskorej doby bronzovej. V mladšej dobe bronzovej je krajina využívaná v celom rozsahu a hustá sieł sídlisk zahŕňa aj polohy na lokalite Ivanovice na Hané (polohy

\footnotetext{
Príspevok vznikol v rámci projektu grantovej agentúry VEGA „Metalurgia a využitie farebných kovov v mladšom praveku až vo včasnom stredoveku na Slovensku“" (02/0115/18).
} 
s označením 6 a 7), ktoré zanikali spolu s väčšinou ostatných, a to už v stupni HA2. Následne dochádza ku koncentrácii osídlenia stupňov HB1-HB3 iba v priestorovo obmedzenej časti sledovaného regiónu; jeho juhovýchodná čast’ vykazuje jasnú absenciu aktivít - jedinou výnimkou je prezentované nákončie. Táto situácia pretrváva aj v dobe halštatskej a dobre ilustruje prakticky úplnú absenciu lokalít neskorej doby bronzovej a halštatskej na kompletne skúmanej trase dialnice Brno - Kroměříž. Zhluky lokalít dobre korešpondujú s výskytom výšinných sídlisk stupňov HB-HD. Z hladiska tejto štúdie je ale nutné uviest', že predmetná poloha sa nachádza na východnom okraji systematicky sledovaného regiónu a z blízkych katastrov Nezamyslíc (vo vzdialenosti $3 \mathrm{~km}$ ) a Koválovic $(6 \mathrm{~km})$, sú známe doklady sídliskových aktivít neskorej doby bronzovej.

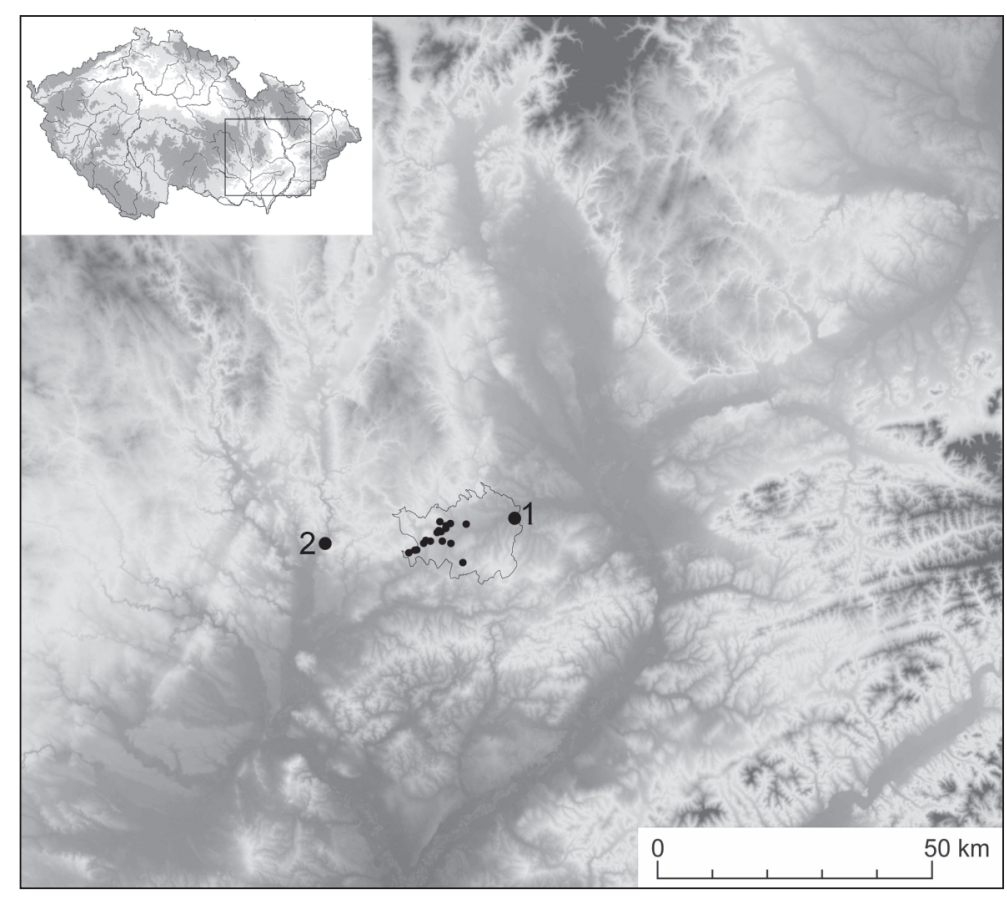

Obr. 1. Poloha lokalít s nálezmi plutvovitých nákončí na Morave (1 - Ivanovice na Hané, 2 - Brno-Obřany) s vyznačenou sídliskovou štruktúrou v stupni HB v priestore Vyškovskej brány.
V rokoch 2014-2015 bol pracovníkmi Ústavu archeologickej památkovej péče Brno realizovaný s podporou Grantovej agentúry ČR projekt (GAČR 14 - 3317OP) „Archeologie střední a mladší doby bronzové - kontext a informační potenciál rozsáhlých záchranných výzkumů". Jeho súčastou bolo vyhodnotenie rozsiahlych záchranných výskumov na trase dial'nice D1 u Vyškova v rokoch 2002-2003 a realizácia nových prospekčných prác na vytipovaných sídelných komponentoch strednej a mladšej doby bronzovej $\mathrm{v}$ katastri Ivanovíc na Hané (okr. Vyškov). Tie spočívali $\mathrm{v}$ aplikácii plošnej magnetometrickej prospekcie, povrchových zberov a dalej zberov s použitím detektorov kovov (Parma/Holubová/Rybářová 2016, 21; Parma a i. 2017, 63-94). Informácie o všetkých vytipovaných lokalitách sú dostupné v literatúre a povedomie o realizovaných výskumoch je aj u miestnej verejnosti rozšírené. Vo všetkých prípadoch

teda ide o polohy, z ktorých sú dlhodobo a podla platných stôp aj pomerne intenzívne získavané kovové nálezy. Systematický prístup ale umožnil v niektorých polohách získat na jednej strane početné nálezové súbory, ktoré súviseli so sídliskovými areálmi mladšej doby bronzovej, na strane druhej aj ojedinelé nálezy z iných období - jedným z nich je aj v tejto štúdii diskutovaný unikátny nález plutvovitého nákončia, ktoré bolo súčastou výbavy bojovníka neskorej doby bronzovej. Na základe paralel sa tento typ mohol vyskytovat pravdepodobne spolu s dýkou alebo s mečom.

\section{NÁLEZISKO IVANOVICE NA HANÉ A METÓDA ARCHEOLOGICKÉHO VÝSKUMU}

Lokalita Ivanovice na Hané, poloha 7 Spravedlnost, sa nachádza po oboch stranách dialničnej trasy D1, na miernom severnom a východnom svahu na lavom brehu Švábenického potoka, približne $11 \mathrm{~km}$ východne od centra dnešného mesta Vyškov (obr. 1). Medzi významné nálezy, ktoré sa objavili počas týchto záchranných výskumov na trase dial’nice Brno - Kroměříž, sa zaradil aj unikátny nález plutvovitého nákončia (obr. 2: 1; Parma/Holubová/Rybárová 2016, 25, tab. 1). Podarilo sa ho získat počas výskumu pomocou detektora kovov. $Z$ tejto polohy pochádza najpočetnejšia kolekcia 26 artefaktov rámcovo datovaných do mladšej doby bronzovej a dva predmety z iného obdobia (Parma a i. 2017, 79, obr. 4: 23). $\mathrm{Z}$ geomorfologického hladiska ide o polohu $\mathrm{v}$ priestore Ivanovickej brány, ktorá tvorí severovýchodný okraj Vyškovskej brány, ktorý patrí do sústavy vnútrokarpatských zníženin (spája Hornomoravský a Dyjsko-svratecký úval). Charakteristickým krajinným rysom tejto oblasti je plochý reliéf so široko za- 
oblenými rozvodnými chrbtami a roztvorenými údoliami. Väčšie vodné toky sú sprevádzané údolnými nivami a menej častými riečnymi terasami (Demek/Mackovčin 2006). Ide o vyústenie prirodzeného komunikačného koridoru, ktorý spája oblast’ Brněnska na juhozápade s nížinou na Hanej na severovýchode, jeho os tu tvorí tok riečky Haná, ktorá je pravobrežným prítokom Moravy. Poloha je v súčasnej dobe využívaná ako pole a vzhl’adom k hrúbke ornice a pôdneho typu $(0,3+0,2 \mathrm{~m})$ pochádzajú všetky nálezy predovšetkým z tých vrstiev, ktorých sa dotkla orba. Skupina zberatel’ov (3-6 osôb) v rámci povrchového prieskumu systematicky prechádzala pásy v šírke $15 \mathrm{~m}$, postupne presúvané v priestore, pomocou GPS stanice Trimble R4 zameriavala polohu všetkých objavených artefaktov. Výsledný obraz je pomerne reprezentatívny, celkovo sa v polohe $7 \mathrm{v}$ Ivanoviciach na Hané podarilo získat' 25 artefaktov a 33 zliatkov a náliatkov datovaných do mladšej doby bronzovej, po jednom artefakte zo staršej doby bronzovej, doby laténskej a stahovonia národov, dva predmety z doby rímskej a jediné nákončie, ktoré je datované do neskorej doby bronzovej (Parma a i. 2017, obr. 4: 18, 4: 19; tab. 4: 2).

\section{NÁLEZ PLUTVOVITÉHO NÁKONČIA POŠVY A VÝSLEDKY TECHNICKÉHO MERANIA}

\section{Opis nálezu a analýza kovu}

Liate plutvovité nákončie; oválna tulajka má dlhšiu os prierezu otočenú oproti plutvovitému zakončeniu o $90^{\circ}$; v polovici dížky jeden upevňovací otvor; dí.: $56 \mathrm{~mm}$; max. šír.: $17 \mathrm{~mm}$; hmotnost:: $28,9 \mathrm{~g}$. Uloženie: Múzeum Vyškovska (inv. č. A117 178). Z vnútornej steny artefaktu bolo po zakonzervovaní odvŕtané menšie množstvo kovových pilín, ktoré boli následne analyzované ručným energo disperzným XRF prístrojom (pXRF) Inno X Delta Professional, v režime Geochem (Vanad) po dobu 3 x 20 sekúnd. Výber z výsledných hodnôt ppm. Ni 999, Cu 434 042, Zn nezistený, As 1925, Ag 411, Sn 11 993, Sb 867, Au nezistené, Pb 2129, Bi 27, lahké prvky súhrnne 323 535, A 7989, Fe 1057. Materiál je možné interpretovat’ ako med's nízkou prímesou cínu (asi 2,5\%), ktoré nemusí byt nutne výsledkom úmyselného legovania, a d’alej so stopovým obsahom arzénu, antimónu a olova. L'ahké prvky spolu s hliníkom je možné považovat za kontamináciu koróznymi produktami z pôdy a zvyškov konzervačného vosku (tabela 1).

Tabela 1. Chemické zloženie zliatiny na základe pXRF merania odvŕtaných vzoriek nákončí z Ivanovíc n. H. a BrnaObřan (meranie J. Petř́ik).

\begin{tabular}{|l|l|l|l|l|l|l|l|l|l|l|l|l|l|}
\hline & $\mathbf{N i}$ & $\mathbf{C u}$ & $\mathbf{Z n}$ & $\mathbf{A s}$ & $\mathbf{A g}$ & $\mathbf{S n}$ & $\mathbf{S b}$ & $\mathbf{A u}$ & $\mathbf{P b}$ & $\mathbf{B i}$ & $\mathbf{A l}$ & $\mathbf{F e}$ & Spolu \\
\hline Ivanovice na Hané & 0,22 & 94,07 & 0,00 & 0,42 & 0,09 & 2,59 & 0,19 & 0,00 & 0,46 & 0,01 & 1,73 & 0,23 & $100 \%$ \\
\hline Brno-Obřany, hrob 169 & 0,33 & 91,39 & 1,25 & 0,70 & 0,05 & 3,60 & 0,07 & 0,00 & 2,37 & 0,01 & 0,01 & 0,22 & $100 \%$ \\
\hline
\end{tabular}

\section{KULTÚRNE A CHRONOLOGICKÉ VYHODNOTENIE NÁLEZU Z IVANOVÍC NA HANÉ V KONTEXTE VÝVOJA MLADŠEJ A NESKOREJ DOBY BRONZOVEJ}

Pri plutvovitom nákončí z Ivanovíc na Hané (obr. 2: 1) ide o ojedinelý nález, ktorý sa nenašiel v sídliskovom, ani pohrebiskovom kontexte. Ide o výnimočný predmet a je zaujímavé, že aj druhý exemplár pochádza z lokality na Morave, a to z hrobu 169 z Brna-Obřan (obr 2: 2). Medzi oboma náleziskami je vzdušnou čiarou vzdialenost iba necelých $45 \mathrm{~km}$. Publikoval ho F. Adámek (1961) v monografii o tomto významnom hradisku a pohrebisku a neskôr V. Podborský (1970, 68; 1994; Podborský a kol. 1993, 292-295). Na kontakty k regiónom severného Pričiernomoria a severného Kaukazu poukazuje plutvovité nákončie, ktoré na základe doterajších poznatkov bolo publikované ako bronzové, pretože analýzy chýbali. V hrobovom inventári 169 z Brna-Obřan sa d’alej nachádzal aj železný meč s jazykovitou rukovätou, ktorý dokladá kontakty s grécko-egejskou oblastou (Stegmann-Rajtár 1986, 213, 214, tab. 2: 1). Ide o meč dalmátsko-panónskeho typu, ktorý sa vyrábal z bronzu, iba v dvoch prípadoch poznáme jeho železné vyhotovenie. Rozšírenie tak bronzových, ako aj železných exemplárov, ktoré poznáme z juhovýchodnej Európy, publikovala S. Pabst. Práve v súvislosti s hrobom 169 z Brna-Obřan a z jaskyne Škocjan/Mušja jama v Slovinsku ide o exempláre vyhotovené zo železa (Pabst 2009, 55-57, obr. 6). 
Na základe rozšírenia plutvovitého typu nákončia v severnom Pričiernomorí a na severnom Kaukaze je doložený ich spoločný výskyt s dýkami, alebo ojedinele aj s mečmi, tam sa nachádzala centrálna oblast' ich výskytu (obr. 3; Metzner-Nebelsick 2002, 378, obr. 171). Zobrazenia kimerských bojovníkov sú známe aj z kamenných stél, ktoré sa $\mathrm{v}$ niektorých prípadoch zachovali na hrobových miestach pochovaných $\mathrm{v}$ severokaukazskej a pričiernomorskej oblasti. Znázornenie dýky s nákončím je doložené napríklad na antropomorfnej kamennej stéle z Kyzburunu $\mathrm{v}$ oblasti Baksan v Balkarii (Batčaev/Kerefov 1980, 291, obr. 2).

Plutvovité nákončia (väčšie aj menšie exempláre) tvorili súčast’ výbavy kimerských bojovníkov. Zbraň - dýku alebo meč - nosili tradične za opaskom, ktorého súčastou bola zvyčajne aj tulajkovitá sekera a kamenný brúsik. Rovnaký typ nákončia poznáme aj z hrobu 169 z Brna-Obřan. Plutvovité nákončia sa vyskytujú spolu s dýkami alebo mečmi typu Gamów-Pjatigorsk, resp. Kabardino-Pjatigorsk. V prípade dýk ide o celobronzové alebo bimetalické dýky typu Kabardino-Pjatigorsk, ktoré sa ako importy dostali až do strednej Európy (Kossack 1980; Metzner-Nebelsick 2002, obr. 167; 371). $\mathrm{Z}$ územia juhozápadného Slovenska pochádza už dávnejšie známy nález ojedinelej bronzovej dýky typu Pjatigorsk-Golovjatino, resp. typu Kabardino-Pjatigorsk z Malého Cetína, okr. Nitra. Nie je vylúčené, že mohlo íst' o hrobový nález, ked’že nálezca spomínal aj črepy hlinenej nádoby, ktoré sa však nezachovali (Bátora 2001, 435-437). V poslednom období pribudli z územia Slovenska dva nálezy dýk s krížovou prelamovanou rukovätou, ktoré boli vyhotovené zo železa a patria $\mathrm{k}$ typu Gamów, resp. Pjatigorsk-Golovjatino. Prvá pochádza z neznámej lokality, údajne z priestoru Slovenskej brány, a druhá z bližšie neznámej polohy v Dolných Vesteniciach, okr. Prievidza (Čambal 2017, 350, pozn. 2).

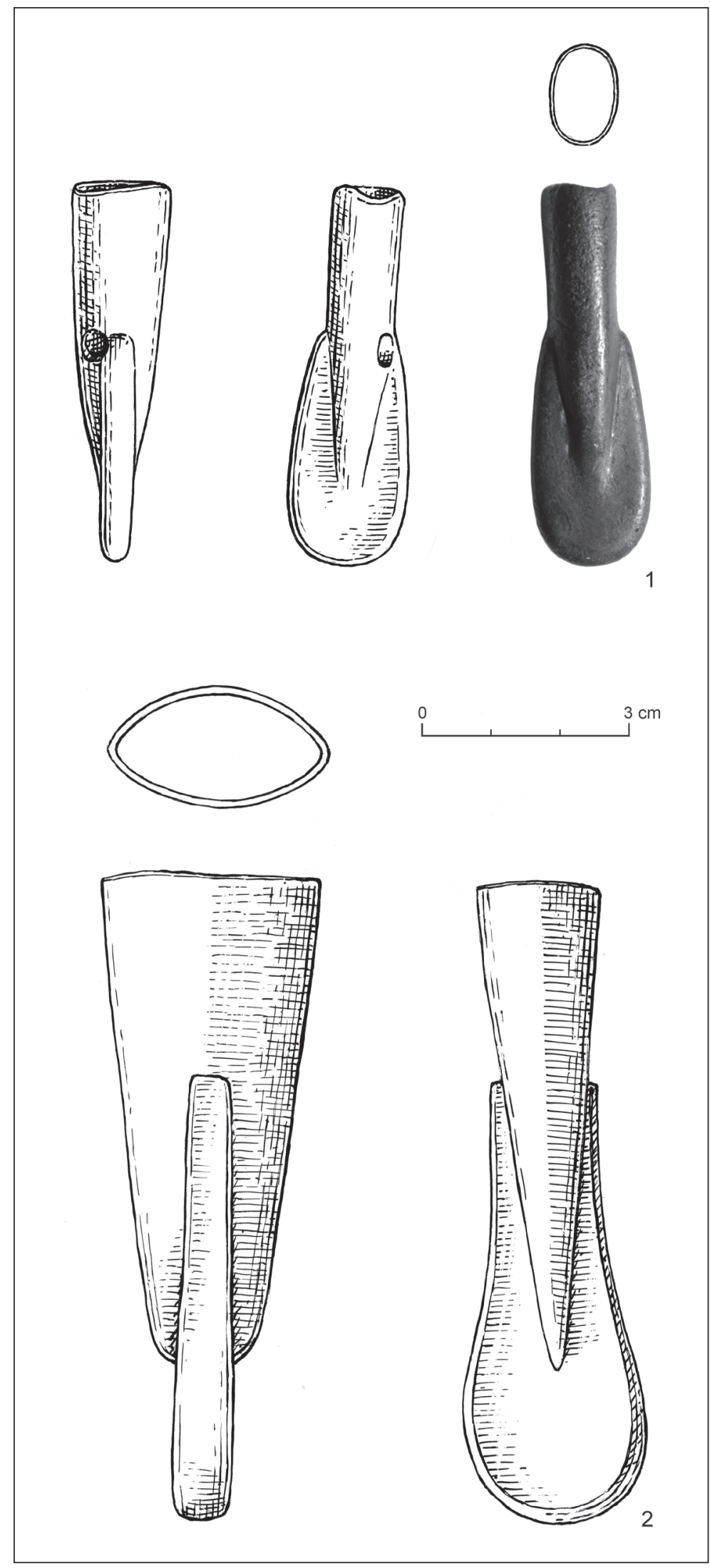

Obr. 2. Nálezy plutvovitých nákončí (pravdepodobne meča alebo dýky). 1 - Ivanovice na Hané; 2 - Brno-Obřany, z hrobu 169 (1 - podla Parma a $i$. 2017, obr. 4; 2 - podla Stegmann-Rajtár 1986, tab. 2: 6). 
Ide o typy dýk, pri ktorých je vel'mi pravdepodobné, že sa používali spolu s nákončím plutvovitého tvaru, tak ako ich poznáme v ich pôvodných miestach výskytu. Chronologické postavenie týchto dýk, ako aj plutvovitých nákončí súhrnne publikovala S. Reinhold, ktorá sa podrobne zaoberala vývojom kobanskej kultúry v pričiernomorskej a kaukazskej oblasti. Tieto typy nálezov sú typické pre kobanskú kultúru a sú datované do 10. stor. pred n. 1. (Reinhold 2007, obr. 109; 232). Na základe analýzy materiálu sa zistilo, že plutvovité nákončia sa najčastejšie objavili v sprievode dýk s prelamovanou rukovätou typu Kabardino-Pjatigorsk, ktoré boli charakteristické pre kobanskú kultúru severokaukazskej oblasti a boli rozšírené v 10. stor. pred n. 1. (Reinhold 2007, 43). C. Metzner-Nebelsick sa detailne zaoberala problematikou rozšírenia kimerských nálezov, okrem iného aj dýk s krížovou rukovätou, a to bud' s prelamovanou (typ Gamów-Pjatigorsk), alebo plnou rukovätou (typ Leibnitz-Golovjatino), pričom čerpala poznatky z prác G. Kossacka (1980), V. Podborského (1970, 147-172, obr. 25; 26) a V. I. Kozenkovej (1975). Kozenkova zaviedla do literatúry typ Kabardino-Pjatigorsk, resp. Gamów. Ide o bimetalické dýky, ktoré mali rukovät’ vyrobenú z bronzu a čepel’ zo železa. Pritom včasné typy bimetalických dýk sa objavili v severopontskej stepnej oblasti už v hroboch belozerskej kultúry doby bronzovej (Metzner-Nebelsick 2002, 373). Najstaršie dýky uvedených typov boli vyhotovené z bronzu a slúžili aj ako predloha pre výrobu bimetalických, a tiež železných dýk. Mapu rozšírenia dýk, ktoré publikovala Metzner-Nebelsick môžeme doplnit o nové nálezy posledných rokov z Malého Cetína, Dolných Vestenic a Slovenskej brány (Čambal 2017). K najstarším dýkam typu Gamów-Pjatigorsk, resp. Kabardino-Pjatigorsk, ktorého prelamovaná rukovät pozostáva z jedného radu kruhových otvorov, patrilo aj plutvovité nákončie z hrobu v Klin-Jar pri Kislovodsku (Andreeva/Kozenkova 1986). V depote z náleziska Gamów sa tento typ dýky objavil spolu so sponou typu Spindlersfeld a datuje sa do stupňa HB1, čiže do 11. stor. pred n. l. Železný meč spolu s plutvovitým nákončím pochádza aj z hradiska Subbotov (ukrajinská lesostep), kde tieto nálezy patria najneskôr do 9. stor. pred n. 1. (Kossack 1980, 110; Terenožkin 1976, obr. 50). Tieto typy nálezov sú typické pre kobanskú kultúru a sú datované do 10. stor. pred n. 1. (Reinhold 2007, obr. 109; 232). Plutvovité nákončie z hrobu 169 z Brna-Obřan datujeme do 9., najneskôr na začiatok 8. stor. pred n. 1. (Stegmann-Rajtár 1986, 214; 1994, 324-327).

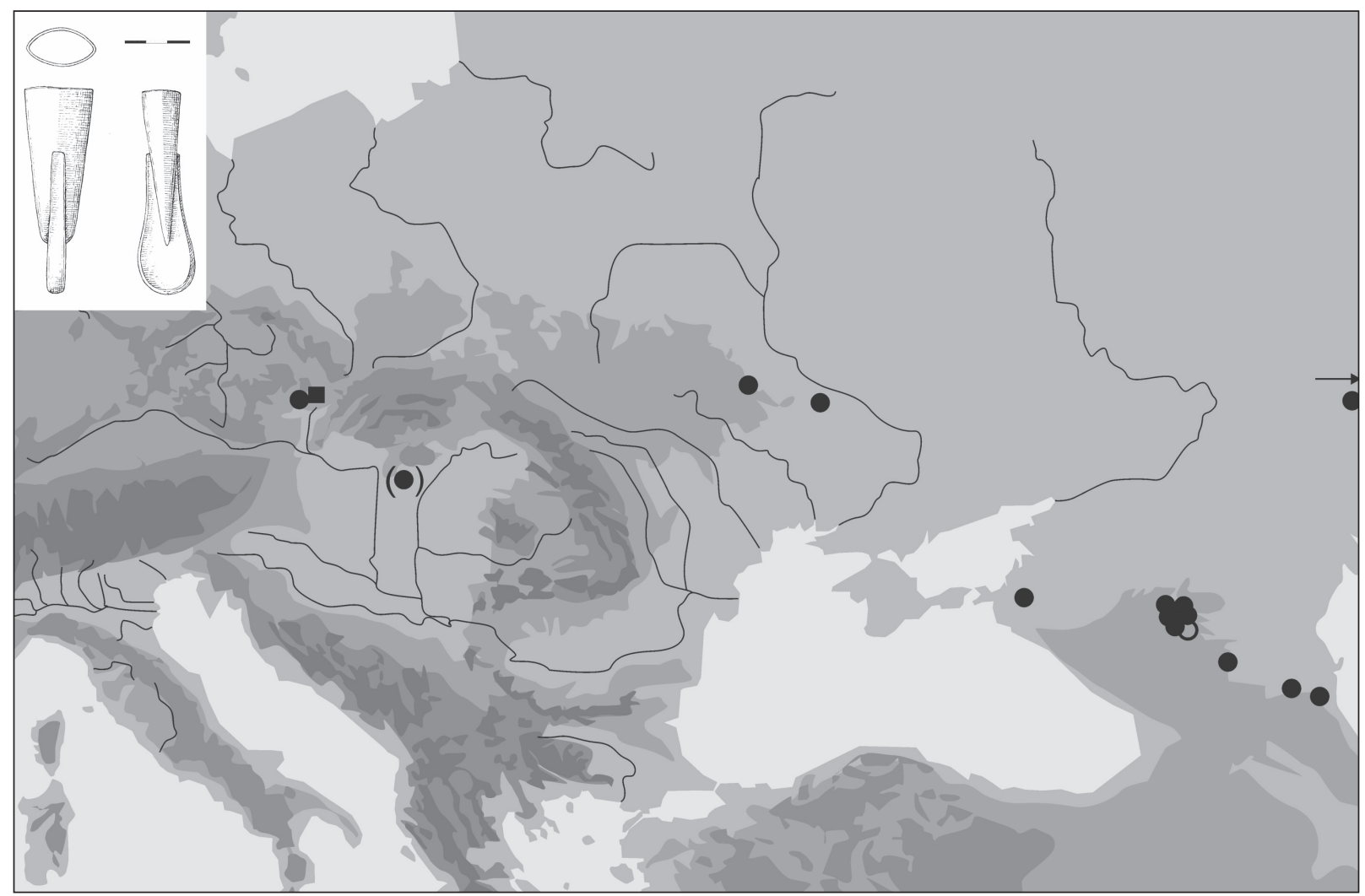

Obr. 3. Rozšírenie plutvovitého typu nákončia (podla Metzner-Nebelsick 2002, obr. 171). Doplnené je nálezisko Ivanovice na Hané, okr. Vyškov (štvorec). 


\section{ZÁVER}

Ojedinelý nález z Ivanovíc na Hané ku ktorému nepoznáme kontext, ani bližšie nálezové okolnosti, vieme interpretovat iba na základe už dávno známeho nálezu zo žiarového hrobu 169 v Brne-Obřanoch. Medzi oboma náleziskami je vzdušnou čiarou vzdialenost̉ iba necelých $45 \mathrm{~km}$. Vyhodnotenie archeologických výskumov na tejto lokalite centrálneho významu sa dnes stalo už súčastou dejín moravskej archeológie. Terénne výkopy na pohrebisku a na hradisku v Brne-Obřanoch od roku 1885 uskutočňovali najmä členovia brnianskeho Múzejného spolku a neskôr vo výskume pokračovali aj mnohí profesionálni archeológovia (Adámek 1961, 21; Podborský 1970, 68; Podborský a kol. 1993). Komplexné dokumentovanie a vyhodnotenie tak staršieho, ako aj novšieho materiálu je však vel’mi zdíhavé a náročné a práve z tohto dôvodu sa ho dodnes nepodarilo uspokojivo ukončit (KmetoválStegmann-Rajtár 2015, 74-77; Podborský 1994, 206). Ostrožné hradisko, ktoré sa rozprestieralo na predpolí Moravského krasu, bolo z troch strán obmývané riekou Svitavou a malo velmi výhodnú strategickú polohu. Postupne sa na tomto mieste podarilo vybudovat' mocenské, hospodárske a politické centrum, ktoré vzniklo na rozhraní podolskej a lužickej kultúry (Stegmann-Rajtár 1992a, 36). Pohrebisko sa nachádzalo v bezprostrednej blízkosti hradiska, a to v polohách Široké, Úzke a Př́ční. Zo zisteného počtu 263 hrobov sa podarilo preskúmat celkove 169. Na základe predpokladu V. Podborského $(1994,208)$ je však velmi pravdepodobné, že tu bolo uložených až okolo 2000 hrobov. Počiatky osídlenia spadajú do obdobia velaticko-podolskej kultúry, teda na prelom 11. a 10. stor. pred n. 1. Najväčší rozmach zažívalo hradisko aj pohrebisko v mladšej a neskorej dobe popolnicových polí, teda v 10. a 9. stor. pred n. l. Obrovský počet a rôznorodost nálezov poukazuje na jeho klúčový význam nielen v rámci kultúrneho vývoja stredoeurópskeho regiónu. Mnohé mimoriadne nálezy sú dokladom jeho nadregionálnych kontaktov so vzdialenými oblastami nielen južnej a juhovýchodnej Európy, ale aj s pričiernomorskou a kaukazskou oblastou. Nové poznatky sa získali vd’aka žiarovému hrobu 169, ktorého miesto v kultúrnom vývoji popolnicových polí bolo vyhodnotené už dávnejšie (Adámek 1961; Podborský 1994; Stegmann-Rajtár 1986; 1992a; 1994). Tento hrob bol v porovnaní s inými hrobovými celkami odkrytými na tomto rozsiahlom pohrebisku výrazne odlišný. Patril jazdcovi - bojovníkovi, ktorý reprezentoval elitu vtedajšej spoločnosti. V sprievode keramiky typickej pre neskorú dobu popolnicových polí výrazným spôsobom poukazuje na symbiózu podolskej a lužickej kultúry. Vyskytli sa v ňom aj unikátne bronzové a železné nálezy, niektoré cudzej proveniencie, okrem iného meč s jazykovitou rukovätou juhoeurópskeho pôvodu, ktorý sa tradične vyrábal z bronzu, avšak exemplár z Moravy už bol vyrobený zo železa (Pabst 2009, 57, obr. 6; Stegmann-Rajtár 1986). V inventári sa okrem plutvovitého nákončia nachádzala aj unikátna železná kopija s dvomi otvormi v spodnej časti listovitej čepele. Na základe nadregionálnych súvislostí bol hrob 169 zaradený do 9., najneskôr na začiatok 8. stor. pred n. 1. (KmetoválStegmann-Rajtár 2015, 74-77; Stegmann-Rajtár 1986; 1992a, 36-42; 1994, 321-327). Kedže na lokalite Ivanovice na Hané neboli objavené žiadne hroby z neskorej doby popolnicových polí, a ani súdobé sídlisko ako bola koncentrácia takýchto lokalít ned’aleko Brna (napr. Podolí alebo Brno-Obřany; ide o klúčové pohrebiská v podolskej kultúre (typ Podolí-Stillfried; KmetoválStegmann-Rajtár 2015; Stegmann-Rajtár 1992a; 1994), v priestore na rozhraní podolskej a lužickej kultúry. Poukazuje to skôr na možnost', že plutvovité nákončie jeho majitel' s vel'kou pravdepodobnostou mohol stratit pri prechádzaní týmto územím. Vylúčit sa dá aj možnost', že by išlo o depot $\mathrm{v}$ týchto miestach. Zdá sa preto najpravdepodobnejšie, že patrí do rovnakého obdobia, ako jeho paralela z hrobu 169 z Brna-Obřan, ktorá patrí na základe ostatných nálezov do obdobia neskorej doby bronzovej, teda do 9. alebo na prelom 9./8. stor. pred n. l., ked' sa aj na Moravu rozšírili nálezy kimerského typu vyrobené z bronzu alebo železa, príp. $\mathrm{v}$ niektorých prípadoch išlo o bimetalické predmety. Istou otázkou je však skutočný koniec sídlisk s takou keramikou, ktorá štýlovo odpovedá stupňu HA, lebo najmladší absolútny dátum priamo z polohy Ivanovice na Hané 7 spadá až do 10. stor. pred n. 1. (Parma a i. 2017, obr. 5: 70), čo by hypotetickú súčasnost’ so súdobým osídlením nevylučovalo. Postupné prehodnotenie starších nálezov a stále viac pribúdajúcich nových predmetov tzv. kimerského typu v Karpatskej kotline, ako aj západne od nej, dáva jasnejší pohlad na ich postavenie v centrálnej Európe. Mnohé nálezy, napríklad niektoré typy konského postroja sa vyrábali už v Karpatskej kotline, hoci jednoznačne ide o typy, ktorých pôvod bol v pričiernomorskej oblasti a v regióne severne od Kaukazu (Metzner-Nebelsick 2002, 369-470). Iná je interpretácia dýk a mečov, ktoré sa zrejme všetky dostávali do Karpatskej kotliny ako importy (Metzner-Nebelsick 2002, 369-470). To s vel'kou pravdepodobnostou platí pre typ plutvovitého nákončia z hrobu 169 z Brna-Obřan, ako aj pre ojedinelý nález z lokality Ivanovice na Hané. 
V hroboch doby halštatskej sa tento typ nákončia už nevyskytoval. Informácia o údajnom náleze plutvovitého nákončia z mohyly 1 v Brne-Holáskach sa nezakladá na skutočnosti. ${ }^{2}$

\section{LITERATÚRA}

Adámek 1961

Andreeva/Kozenkova 1986

Batčaev/Kerefov 1980

Bátora 2001

Čambal 2017

Demek/Mackovčin 2006

Kmet'ová/Stegmann-Rajtár 2015

Kossack 1980

Kozenkova 1975

Metzner-Nebelsick 2002

Pabst 2009

Parma 2015

Parma/Šmíd 2013

Parma/Holubová 2015

Parma/Holubová/Rybářová 2016

Parma a i. 2017

Podborský 1970

Podborský 1994

Podborský a kol. 1993

Reinhold 2007
F. Adámek: Pravěké hradisko u Obřan. Brno 1961.

M. V. Andreeva/V. I. Kozenkova: Kompleks načala I. tysjačeletija do n.e. iz uročišča Klin-Jar (Kislovodskaja kotlovina). Sovetskaja archeologija 1, 1986, 253-258.

V. M. Batčaev/B. M. Kerefov: Olenyj kamen iz Kabardino-Balkarii. Sovetskaja archeologija 3, 1980, 289-294.

J. Bátora: Der Fund eines Bronzedolches aus dem Zeitabschnitt des sog. thrakokimmerischen Horizontes in Malý Cetín (Bez. Nitra), SW Slowakei. Pravěk. Nová rada 10, 2001, 435-448.

R. Čambal: Železná dýka typu Gamów trácko-kimerského horizontu zo Slovenska. In: N. Beljak Pažinová/Z. Borzová (ed.): Sedem decénií Petra Romsauera. Studia Historica Nitriensia. Supplementum - mimoriadne číslo časopisu venované životnému jubileu prof. Petra Romsauera. Nitra 2017, 349-356.

J. Demek/P. Mackovčin (ed.): Hory a nížiny. Zemepisný lexikon ČR. Brno 2006.

P. Kmetová/S. Stegmann-Rajtár: Symbolické uloženie lebky koňa v hroboch v závere doby popolnicových polí a v počiatkoch doby halštatskej. In: O. Oždáni (ed.): Popolnicové polia a doba halštatská. Zborník referátov z XII. medzinárodnej konferencie Doba popolnicových polí a doba halštatská. Hriňová-Polana 14.-18. máj 2012. Nitra 2015, 73-92.

G. Kossack: „Kimmerische“ Bronzen. Bemerkungen zur Zeitstellung in Ost- und Mitteleuropa. Situla 20/21, 1980, 109-143.

V. I. Kozenkova: K voprosu o rannej date nekotorych kinžalov tak nazyvajemogo kabardino-pjatigorskogo tipa. In: Trako-Skifskie kulturnyje svjazi. Studia Thracica 1. Sofia 1975, 91-102.

C. Metzner-Nebelsick: Der "Thrako-Kimmerische“ Formenkreis aus der Sicht der Urnenfelder- und Hallstattzeit im südöstlichen Pannonien. Vorgeschichte Forschungen 23. Rahden/Westf. 2002.

S. Pabst: Bevölkerungsbewegungen auf der Balkanhalbinsel am Beginn der Früheisenzeit und die Frage der Ethnogenese der Makedonen. Jahrbuch des Deutschen archäologischen Instituts 124, 2009, 1-74.

D. Parma: Poznámky k sídelním strukturám starší a strední doby bronzové na jižní Moravě. In: J. Bátora/P. Tóth (ed.): Ked’ bronz vystriedal med'. Bratislava - Nitra 2015, 243-260

D. Parma/M. Šmíd: Sídelní areály střední a mladší doby bronzové z trasy dálnice D1 u Vyškova. Katalog 2. Brno 2013.

D. Parma/Z. Holubová: Záchranné výskumy v Habrovanech a otázka pozdně bronzového osídlení Vyškovské brány. Pravěk. Nová řada 23, 99-148.

D. Parma/Z. Holubová/K. Rybářová: Sídelní struktury doby bronzové v oblasti Vyškovské brány. Studia Archaeologica Brunensia 21, 2016, 21-45.

D. Parma/P. Barta/ Z. Holubová/L. Horáčková/I. Jarošová/J. Kala/S. Kaupová/R. Křivánek/M. Nývltová-Fišáková/A. Přichystal/M. Roblíčková/Z. Tvrdý/H. Nohálková/L. Vargová: Archeologie střední a mladši doby bronzové na Vyškovsku. Brno 2017. V. Podborský: Mähren in der Spätbronzezeit und an der Schwelle der Eisenzeit. Brno 1970.

V. Podborský: Postavení obřanského hradiska v době popelnicových polí ve středoevropském regionu. Pravěk. Nová řada 4, 1994, 205-232.

V. Podborský a kolektiv: Praveké dejiny Moravy. Brno 1993.

S. Reinhold 2007: Die Spätbronze- und frühe Eisenzeit im Kaukasus. Materielle Kultur. Chronologie und Überregionale Beziehungen. Universitätsforschungen zur Prähistorischen Archäologie 14. Bonn 2007.

\footnotetext{
2 Údaj o plutvovitom nákončí, publikovanom v Pravěkých dejinách Moravy, údajne pochádzajúcom z mohyly 1 z Brna-Holások (Podborský a kol. 1993, 349, obr. 230: 25), ktorá patrí do doby halštatskej (horákovská kultúra), nezodpovedá skutočnosti. Ide o jednoznačne mylnú informáciu, ktorá sa nezakladá na pravdivej skutočnosti. Ďalej je zavádzajúca aj kresba železného meča z tejto mohyly z Brna-Holások (Podborský a kol. 1993, 349, obr. 230: 24), pretože taký typ meča v dobe halštatskej neexistoval. Na základe podrobnej dokumentácie v archíve Moravského zemského muzea v Brne boli autorkou tohto príspevku všetky nálezy pochádzajúce z mohýl 1 a 2 z Brna-Holások kresebovo zdokumentované a následne publikované (Stegmann-Rajtár 1992a, tab. 6: 1; 1992b, tab. 1: 1).
} 
Stegmann-Rajtár 1986

Stegmann-Rajtár $1992 a$

Stegmann-Rajtár $1992 b$

Stegmann-Rajtár 1994

Terenožkin 1976
S. Stegmann-Rajtár: Neuerkenntnisse zum Grab 169 von Brno-Obřany (Mähren). In: L. Török (ed.): Hallstatt-Kolloquium Veszprém 1984. Mitteilungen des Archäologischen Instituts der Ungarischen Akademie der Wissenschaften. Beiheft 3. Budapest 1986, 211-219.

S. Stegmann-Rajtár: Spätbronze- und früheisenzeitliche Fundoruppen des mittleren Donaugebietes. Bericht der Römisch-Germanischen Kommission 73. Mainz am Rhein 1992, 29-179.

S. Stegmann-Rajtár: Grabfunde der älteren Hallstattzeit aus Südmähren. Košice 1992. S. Stegmann-Rajtár: Vývoj stredodunajských popolnicových polí v neskorej dobe bronzovej (HaB) a vznik halštatskej kultúry. Slovenská archeológia 42, 1994, 319-333. A. I. Terenožkin: Kimmerijcy. Kyjev 1976.

\title{
A unique find of a fin-shaped chape from Ivanovice na Hané, Vyškov district, in the context of development of the Urnfield culture in Moravia
}

\author{
David Parma - Susanne Stegmann-Rajtár
}

\author{
Summary
}

\begin{abstract}
The site of Ivanovice na Hané, site 7 Spravedlnost, is located on both sides of D1 motorway, on the slight northern and eastern slopes on the left bank of the Švábenický potok stream, approx. $11 \mathrm{~km}$ east of today's Vyškov town centre. Important finds discovered during the rescue researches along the motorway between Brno and Kroměříz include the unique find of a fin-shaped chape. It was discovered with a metal detector during the investigation. First of all, it is remarkable that no components of the Upper Bronze Age (stages Br D-Ha A2 are classified as the Late Bronze Age and stage Ha B is the Upper Bronze Age) have been detected at the site and only in one case, activities of the subsequent Hallstatt period were detected. 68 archaeologically positive sites with numerous components dated in the wide span from the Neolithic to the Postmedieval period are recorded in this 'trench through the country'. Activities from the Bronze Age have been documented at almost half of the sites (34). Their chronological and spatial distribution, however, is surprising with its irregularity. Fin-shaped chapes are dated in the Late Urnfield period (Ha B2-3). The fact that it is a unique find is noteworthy. It is a unique exemplar, another such item comes from a site in Moravia - burial 169 in Brno-Obřany. It was published in 1961 by F. Adámek in his monograph presenting this important hillfort and the burial ground at this site.

Settlement of Vyškovská brána site in the Bronze Age and Hallstatt period has been recently mapped on the basis of a representative data collection; one of the results following from the historical studies of the settlement is the remarkable discontinuity of the settlement network since the beginning of the Upper Bronze Age. In the Late Bronze Age, the land was fully used and the dense network of settlements includes sites in Ivanovice na Hané (sites indicated by numbers 6 and 7), which disappeared with most other sites as early as stage Ha A2. Later, stages Ha B1-Ha B3 become concentrated only within a spatially limited part of the studied region; its southeastern part shows clear absence of activities. The presented chape is the only exception. The unique find from Ivanovice na Hané without known find contexts or circumstances can be interpreted only on the basis of the previously known find from burial 169 in Brno-Obřany. New information was provided by cremation burial 169 whose role in the cultural development of urnfields had been evaluated before. This burial, which was uncovered as early as 1932, was much richer in comparison with other burials uncovered on this large burial ground. The burial belonged to a rider-warrior who represented the elite of the then society. Together with pottery of the Urnfield culture (vessels of the Podolie as well as Lusatian cultures), unique bronze and iron finds of foreign provenance inlcluding an iron sword with a tongue-shaped handle of south European origin and fin-shaped bronze chape of an iron sword of Pontic-Caucasian type occurred. Based on the supraregional context, burial 169 was classified in the $9^{\text {th }}$ century BC, or in the beginning of the $8^{\text {th }}$ century BC at the latest. It is very probable that the find of the fin-shaped chape from Ivanovice na Hané chronologically falls in the same period as the find of identical type from burial 169 in Brno-Obřany.
\end{abstract}


Fig. 1. Location of the sites with finds of fin-shaped chapes in Moravia (1 - Ivanovice na Hané; 2 - Brno-Obřany) with indicated settlement structure in stage Ha B in the territory of Vyškovská brána.

Fig. 2. Finds of fin-shaped chapes (probably of a sword or a dagger). 1 - Ivanovice na Hané; 2 - Brno-Obřany, burial 169 (1 - after Parma a i. 2017, fig. 4; 2 - after Stegmann-Rajtár 1986, pl. 2: 6).

Fig. 3 Occurrence of fin-shaped chapes (after Metzner-Nebelsick 2002, fig. 171). The site in Ivanovice na Hané, Vyškov district, is added (square).

Translated by Viera Tejbusová

Mgr. David Parma, PhD.

Ústav archeologické památkové péče Brno, v. v. i.

Kaloudova 30

CZ - 61400 Brno

parma@uapp.cz
PhDr. Susanne Stegmann-Rajtár, CSc.

Archeologický ústav SAV

Akademická 2

SK - 94921 Nitra

zuzana.rajtarova@savba.sk 
